\title{
KUALITAS PAPAN PARTIKEL DARI PELEPAH NIPAH DENGAN PEREKAT ASAM SITRAT DAN SUKROSA
}

\author{
MAHDI SANTOSO ${ }^{1,2^{*}}$, RAGIL WIDYORINI ${ }^{3}$, \\ TIBERTIUS AGUS PRAYITNO ${ }^{3}$, \& JOKO SULISTYO ${ }^{3}$
}

\author{
${ }^{1}$ Jurusan Kehutanan, Fakultas Pertanian, Universitas Palangka Raya \\ Jl. Yos Sudarso, Palangka Raya 73112 \\ ${ }^{2}$ Mahasiswa Program Pascasarjana, Program Studi Ilmu Kehutanan, Universitas Gadjah Mada \\ ${ }^{3}$ Departemen Teknologi Hasil Hutan, Fakultas Kehutanan, Universitas Gadjah Mada, \\ Jl. Agro No. 1, Bulaksumur, Sleman, 55281 \\ *Email: mahdisantoso@gmail.com
}

\begin{abstract}
Utilization of natural binder for non-wood composite is still limited. Sucrose and citric acid are potential natural binding agents for composite products. Nipa (Nypa fruticans Wurmb.) was non-wood materials which are potentially to be used as an alternative raw material for particleboards. This study aimed to determine the quality of the nipa frond particleboard bonded with sucrose/citric acid (100/0, 87.5/12.5 and 75/25). Particleboards were manufactured in $25 \mathrm{~cm} \times 25 \mathrm{~cm} \times 1 \mathrm{~cm}$ dimension, the target of density $0.8 \mathrm{~g} / \mathrm{cm}^{3}$. The variables included resin content of $20 \%$, press time of $10 \mathrm{~m}$, pressing temperature of $180^{\circ} \mathrm{C}$ and specific pressure of 3.6 MPa. The physics and mechanics properties of particleboard were tested in accordance to standard JIS A 5908:2003 and surface roughness was measured by following the method performed by Hiziroglu (1996). The results showed that the addition of citric acid to sucrose give a positive effect on most of the properties of the nipa frond particleboards. The particleboard bonded with sucrose/citric acid 87.5/12.5 was able to provide the best results to meet the standards of JIS A 5908: 2003. Characteristics of the particleboard was a density of $0.89 \mathrm{~g} / \mathrm{cm}$, moisture content of $10.21 \%$, thickness swelling of $2.45 \%$, water absorption of $23.55 \%$, surface roughness of $5.13 \mu \mathrm{m}$, internal bonding of $0.39 \mathrm{MPa}$, modulus of rupture of 9.80 MPa and modulus of elasticity of $3.19 \mathrm{GPa}$.
\end{abstract}

Keywords: particleboard, nipa frond, natural binder, sucrose, citric acid.

\section{INTISARI}

Penggunaan perekat alami dan bahan baku non kayu dalam pembuatan papan partikel masih sangat terbatas. Sukrosa dan asam sitrat adalah dua bahan alami yang potensial sebagai perekat alami pengganti perekat sintetik berbasis formaldehida. Nipah (Nypa fruticans Wurmb.) merupakan bahan non kayu yang potensial dijadikan alternatif bahan baku papan partikel. Penelitian ini bertujuan untuk mengetahui kualitas papan partikel pelepah nipah yang direkat dengan sukrosa/asam sitrat (100/0, 87,5/12,5 dan 75/25). Papan partikel yang dibuat berukuran $25 \mathrm{~cm} \times 25 \mathrm{~cm} \times 1 \mathrm{~cm}$, target kerapatan $0,8 \mathrm{~g} / \mathrm{cm}^{3}$. Variabel perekatan antara lain jumlah perekat 20\%, waktu kempa 10 menit, suhu kempa $180^{\circ} \mathrm{C}$ dan tekanan spesifik 3,6 MPa. Sifat fisika dan mekanika papan partikel diuji berdasarkan standar JIS A 5908:2003, kekasaran permukaan diukur menggunakan metode yang dilakukan oleh Hiziroglu (1996). Hasil penelitian menunjukkan bahwa penambahan asam sitrat terhadap sukrosa berpengaruh positif terhadap sebagian besar sifat papan partikel pelepah nipah. Papan partikel pelepah nipah dengan perekat sukrosalasam sitrat 87,5/12,5 mampu memberikan hasil terbaik dengan memenuhi standar JIS A 5908:2003. Karakteristik papan partikel tersebut adalah kerapatan $0,89 \mathrm{~g} / \mathrm{cm}^{3}$, kadar air 10,21\%, pengembangan tebal 2,45\%, penyerapan air 23,55\%, kekasaran permukaan 5,13 um, keteguhan rekat internal 0,39 MPa, keteguhan patah 9,80 MPa dan keteguhan elastisitas 3,19 GPa.

Kata kunci: papan partikel, pelepah nipah, perekat alami, sukrosa, asam sitrat. 


\section{PENDAHULUAN}

Pada beberapa tahun terakhir perekat alami (natural binder/bio-based binders/bio-binders/ bio-based adhesives/bio-adhesives) berkembang dengan sangat cepat, baik menyangkut jenis maupun optimalisasi dari perekat alami yang sudah ada. Salah satu bahan alami yang cukup potensial untuk dikembangkan sebagai perekat alami ialah sukrosa (Umemura et al., 2013, 2014; Lamaming et al., 2013; Widyorini et al., 2016b). Sukrosa ialah disakarida yang tersusun atas glukosa dan fruktosa yang diikat dengan ikatan eter pada atom $\mathrm{C} 1$ unit glukosa dan atom C2 pada unit fruktosa. Sifat lainnya ialah memiliki kelarutan yang tinggi dalam air dan gugus hidroksil $(\mathrm{OH})$ yang melimpah yang memungkinkannya untuk membentuk ikatan hidrogen dengan molekul selulosa dan hemiselulosa pada bahan lignoselulosa (Bock dan Lemieux, 1982).

Kelemahan sukrosa sebagai perekat alami ialah memiliki stabilitas dimensi dan kekuatan rekat yang relatif rendah. Menurut Widyorini et al. (2016b), papan partikel kayu jati yang direkat dengan sukrosa yang berdiri sendiri dan dikempa pada suhu $180^{\circ} \mathrm{C}$ memiliki kualitas yang rendah yaitu dengan nilai pengembangan tebal mencapai $62 \%$ hampir sama dengan pengembangan tebal papan partikel tanpa perekat (66\%). Kelemahan tersebut disebabkan oleh sifat dasar dari sukrosa sendiri yang merupakan bahan dengan nilai kelarutan dan gugus hidroksil yang cukup tinggi. Penambahan asam polikarboksilat (misalnya asam sitrat) dapat mengeliminasi kelemahan tersebut. Mekanisme yang terjadi ialah terbentuknya ikatan silang antara gugus karboksil $(\mathrm{COOH})$ asam sitrat dengan gugus hidroksil $(\mathrm{OH})$ pada sukrosa dan bahan lignoselulosa yang direkat, dimulai dengan dehidrasi dua kelompok karboksil dan kemudian bereaksi dengan gugus hidroksil membentuk ikatan ester (Umemura et al., 2012;
Harifi dan Montazer, 2012). Penelitian tentang penambahan asam sitrat terhadap perekat sukrosa telah mulai dilakukan dalam usaha meningkatkan kualitas papan partikel yang dihasilkan. Hasil penelitian Umemura et al. (2014) membuktikan bahwa penambahan asam sitrat terhadap sukrosa (rasio asam sitrat/sukrosa 25/75) dan kadar perekat $30 \%$ mampu meningkatkan sifat rekat papan partikel limbah kayu lunak. Hasil penelitian Widyorini et al., (2016b) mendapatkan hasil bahwa penambahan asam sitrat $50 \%$ pada sukrosa (rasio sukrosa/asam sitrat 50/50), mampu meningkatkan sifat rekat papan partikel kayu keras, walaupun hasil tersebut masih lebih rendah jika dibandingkan dengan perekat asam sitrat $100 \%$ akan tetapi jauh lebih baik jika dibandingkan dengan sukrosa $100 \%$ pada penelitian yang sama.

Bahan yang dipandang sangat potensial dan belum dimanfaatkan secara maksimal adalah bahan lignoselulosa yang berasal dari non kayu, salah satunya pelepah nipah. Widyorini et al. (2012) menyatakan bahwa pelepah nipah dapat dimanfaatkan sebagai bahan baku komposit dengan kualitas yang cukup baik. Hasil penelitian tersebut menunjukkan bahwa papan partikel pelepah nipah telah memenuhi sebagian besar standar JIS A 5908:2003. Penelitian lain dari Kruse dan Frühwal (2001) juga menyatakan bahwa papan partikel dari pelepah nipah secara umum memiliki karakteristik yang memuaskan untuk keperluan mebel/furniture. Demikian juga dengan hasil penelitian Roliadi et al. (2012) dan Indrawan et al. (2013) menyatakan pelepah nipah mempunyai potensi yang lebih baik dibanding sabut kelapa sebagai bahan baku papan komposit. Dipandang dari segi potensi ketersediaan bahan baku, maka pelepah nipah merupakan sumber partikel yang sangat potensial yaitu mencapai $1,62 \mathrm{x}$ $10^{10} \mathrm{~kg}$ partikel pelepah nipah kering udara per 
bulan, dengan asumsi pohon nipah 5,6 miliar pohon (Subiandono et al., 2011; Lutony, 1993 cit. Lempang, 2013), dengan berat jenis kering udara pelepah nipah 0,21 (Roliadi, et. al., 2012), panjang pelepah rata-rata 3,5 meter (Subiandono et al., 2011), diameter rata-rata $5 \mathrm{~cm}$ dan dalam satu pohon diambil dua pelepah per bulan.

Penelitian menggunakan campuran sukrosa dan asam sitrat yang optimal sebagai perekat pada papan partikel pelepah nipah (non wood material) belum pernah dilakukan. Untuk itu, tujuan dari penelitian ini ialah mengetahui pengaruh penambahan asam sitrat terhadap kualitas papan partikel dari pelepah nipah yang direkat dengan menggunakan sukrosa.

\section{BAHAN DAN METODE}

Pelepah nipah yang dipergunakan berdiameter antara 5-8 $\mathrm{cm}$ dari kelas pelepah tua (berwarna coklat). Berat jenis rata-rata pelepah nipah ialah 0,31. Partikel pelepah nipah yang dipergunakan adalah partikel dengan kulit. Kerapatan tumpukan (bulk density) partikel rata-rata $0,22 \mathrm{~g} / \mathrm{cm}^{3}$ dengan distribusi partikel sebagai berikut, $>10$ mesh $18 \%$, 10-40 mesh 69\%, 40-60 mesh 6\%, 60-100 mesh 4\% dan $<100$ mesh 3\%. Partikel yang dipergunakan untuk penelitian berukuran lolos 10 mesh (=2 mm).

Bahan yang dipergunakan dalam penelitian ini adalah sukrosa teknis (produksi PT. Multi Kimia Raya (MKR) Chemical, Semarang) dan asam sitrat anhidrat (kadar 99,5-101,0\% produksi PT. Budi Strach \& Sweetener Tbk. Indonesia). Sukrosa dan asam sitrat tersebut kemudian dilarutkan dalam air suling dengan kelarutan berturut-turut 50\% dan 60\% berbasis berat. Jumlah perekat yang dipergunakan ialah $20 \%$ berdasarkan berat kering udara partikel. Perbandingan sukrosa-asam sitrat dalam penelitian ini ialah 100/0; 87,5/12,5 dan 75/25. Larutan perekat yang telah dibuat dicampurkan dengan partikel, kemudian dioven selama \pm 24 jam sampai diperoleh kadar air sekitar 2-4\%.

Dimensi papan partikel yang dibuat berukuran 25 $\mathrm{cm} \times 25 \mathrm{~cm} \times 1 \mathrm{~cm}$ dan target kerapatan $0,8 \mathrm{~g} / \mathrm{cm}^{3}$. Variabel proses kempa yang dipergunakan ialah suhu kempa $180^{\circ} \mathrm{C}$, waktu kempa 10 menit dan tekanan spesifik kempa 3,6 $\mathrm{MPa}$.

Papan partikel yang telah berhasil dibuatkan kemudian dikondisikan pada suhu kamar selama kurang lebih tujuh hari dan kemudian papan partikel tersebut diuji dengan mengacu pada standar JIS A 5908 (JIS, 2003) meliputi kerapatan, kadar air, pengembangan tebal, penyerapan air, keteguhan rekat internal, keteguhan patah, dan keteguhan elastisitas. Pengujian kekasaran permukaan menggunakan alat surface roughness tester SRG-4000 (produksi Phase II+Bosworth Instrument) mengacu pada metode yang dipergunakan oleh Hiziroglu (1996).

\section{HASIL DAN PEMBAHASAN}

\section{Kerapatan dan kadar air}

Papan partikel pelepah nipah dapat dibuat tanpa mengalami delaminasi dan memiliki warna coklat tua (Gambar 1). Warna papan partikel ini mirip dengan yang dihasilkan dalam penelitian Umemura et al. (2013) dan Widyorini et al. (2016b) dengan perekat dan suhu kempa yang sama. Nilai rata-rata kerapatan dan kadar air berturut-turut berkisar antara 0,87$0,92 \mathrm{~g} / \mathrm{cm}^{3}$ dan $9,02-11,70 \%$. Nilai rata-rata kerapatan dan kadar air papan partikel berperekat sukrosaasam sitrat dengan perbandingan 100/0;87,5/12,5 dan 75/25 tersebut tidak berbeda secara signifikan. Semua papan partikel yang dibuat telah memenuhi standar JIS 5908:2003 untuk parameter kadar air yang ditetapkan pada kisaran 5-13\%. 


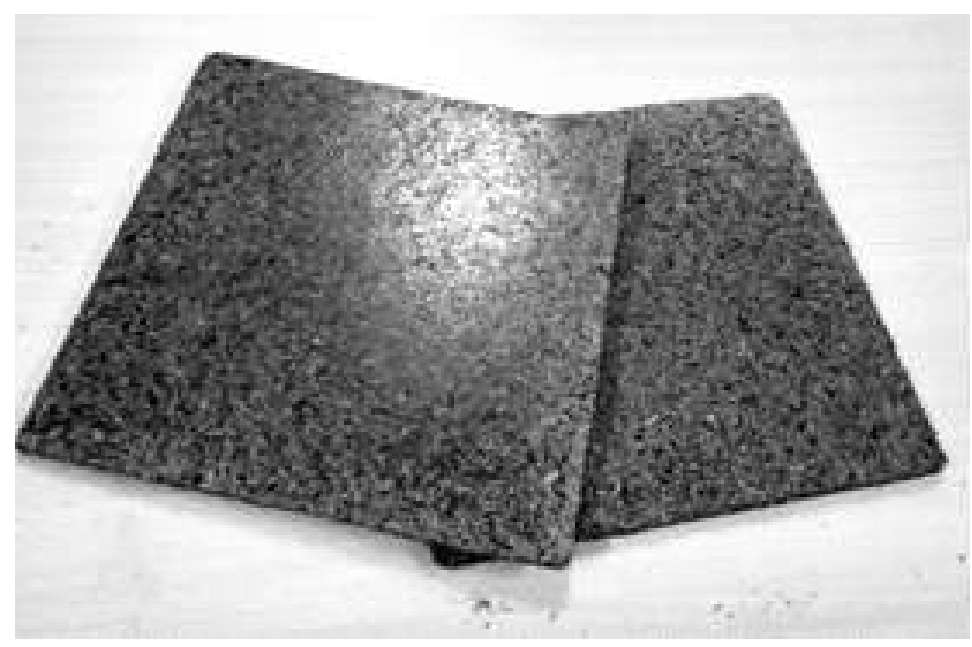

Gambar 1. Papan partikel pelepah nipah dengan perekat sukrosa/asam sitrat $87,5 / 12,5$ kadar perekat $20 \%$

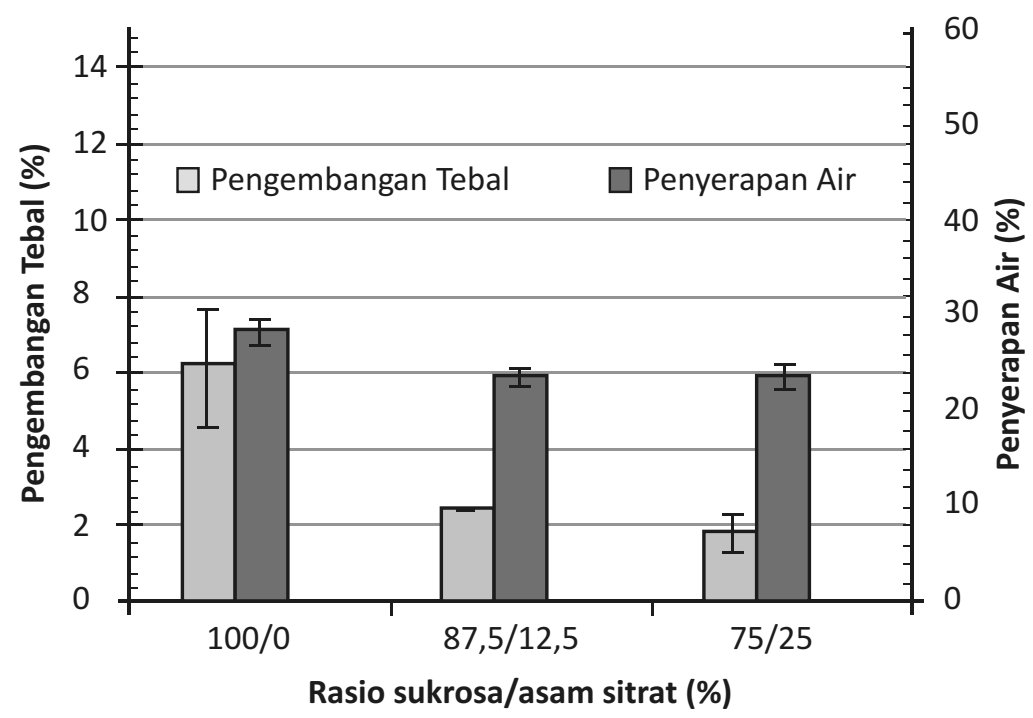

Gambar 2. Histogram stabilitas dimensi papan partikel pelepah nipah. Garis vertika pada bar merupakan standar deviasi.

\section{Stabilitas dimensi}

Stabilitas dimensi ialah kemampuan suatu papan partikel untuk mempertahankan dimensinya terhadap proses perendaman di dalam air (water resistance) dan/atau perubahan kondisi udara sekitar ketika papan tersebut digunakan. Hasil penelitian menunjukkan bahwa nilai rata-rata pengembangan tebal berkisar antara 1,83-6,14\% dan penyerapan air sebesar 23,55-28,36\%. Semua papan partikel pelepah nipah yang dibuat telah memenuhi standar JIS 5908:2003 untuk kategori pengembangan tebal (maksimum 12\%) dan penyerapan air yang relatif rendah di bawah 30\%. Gambar 2 memperlihatkan bahwa penambahan asam sitrat terhadap sukrosa mampu memperbaiki stabilitas dimensi papan partikel dengan penurunan pengembangan tebal tiga kali lipat dibanding papan partikel dengan perekat sukrosa saja. Pengembangan tebal terkecil dihasilkan oleh papan partikel yang direkat dengan sukrosa/ asam sitrat $75 / 25$. Asam sitrat dan kombinasinya dengan sukrosa telah diketahui sebelumnya mempunyai kemampuan yang baik dalam membentuk papan dengan stabilitas dimensi yang baik (Umemura et al., 2013, 2014; Widyorini et al., 
2016b). Asam sitrat telah diketahui berperan besar terhadap berkurangnya gugus hidroksil pada papan partikel dengan mekanisme pembentukan ikatan ester sehingga mampu membentuk papan partikel yang bersifat hidrofobik dengan stabilitas dimensi dan ketahanan terhadap air yang baik (Umemura et al., 2012, 2013, 2014; Widyorini et al., 2016a, 2016b).

\section{Kekasaran permukaan}

Kekasaran permukaan dinyatakan dengan parameter nilai Ra (Roughness average). Nilai rata-rata kekasaran permukaan papan partikel pelepah nipah antara 5,13-7,23 $\mu \mathrm{m}$. Gambar 3 menjelaskan bahwa penambahan asam sitrat mampu memperhalus permukaan papan partikel pelepah nipah secara signifikan. Nilai kekasaran permukaan terbaik dihasilkan oleh papan partikel yang direkat dengan sukrosa/asam sitrat 87,5/12,5 dengan nilai 5,13 $\mu \mathrm{m}$. Menurut Widyorini et al. (2016a), penambahan asam sitrat akan menghasilkan kontak yang lebih baik antara partikel dan memiliki sifat rekat yang lebih baik, yang akan menghasilkan permukaan papan partikel yang lebih halus. Nilai ini telah memenuhi standar kekasaran permukaan papan partikel yang berkisar pada nilai 3,67-5,46 $\mu \mathrm{m}$ (Hiziroglu dan Suzuki, 2007).

\section{Keteguhan rekat internal}

Nilai rata-rata keteguhan rekat internal papan partikel pelepah nipah dapat dilihat pada Gambar 4 . Hasil analisis menyatakan bahwa penambahan asam sitrat berpengaruh sangat nyata terhadap peningkatan keteguhan rekat internal papan partikel pelepah nipah. Peningkatan nilai keteguhan rekat internal papan partikel yang direkat dengan sukrosa dengan penambahan asam sitrat mencapai dua kali lipat daripada tanpa penambahan asam sitrat. Hasil ini serupa dengan hasil penelitian Umemura et al. (2013, 2014) pada papan partikel kayu lunak dan Widyorini et al. (2016b) pada papan partikel kayu keras.

Nilai perbandingan optimal sukrosa/asam sitrat pada papan partikel pelepah nipah ialah pada rasio $87,5 / 12,5$. Rasio ini berbeda dengan nilai optimal yang didapatkan oleh Umemura et al. $(2013,2014)$ pada rasio 75/25 dan Widyorini et al. (2016b) pada rasio 50/50. Perbedaan hasil penelitian ini diduga disebabkan oleh faktor perbedaan jenis bahan baku yaitu kandungan komponen kimia terutama zat ekstraktif dan ukuran partikel yang dipergunakan.

Papan partikel dengan perekat sukrosa/asam sitrat 87,5/12,5 mempunyai nilai keteguhan rekat internal yang paling tinggi. Nilai ini lebih baik jika dibandingkan dengan hasil penelitian yang dilakukan oleh Widyorini et al. (2012) pada papan partikel

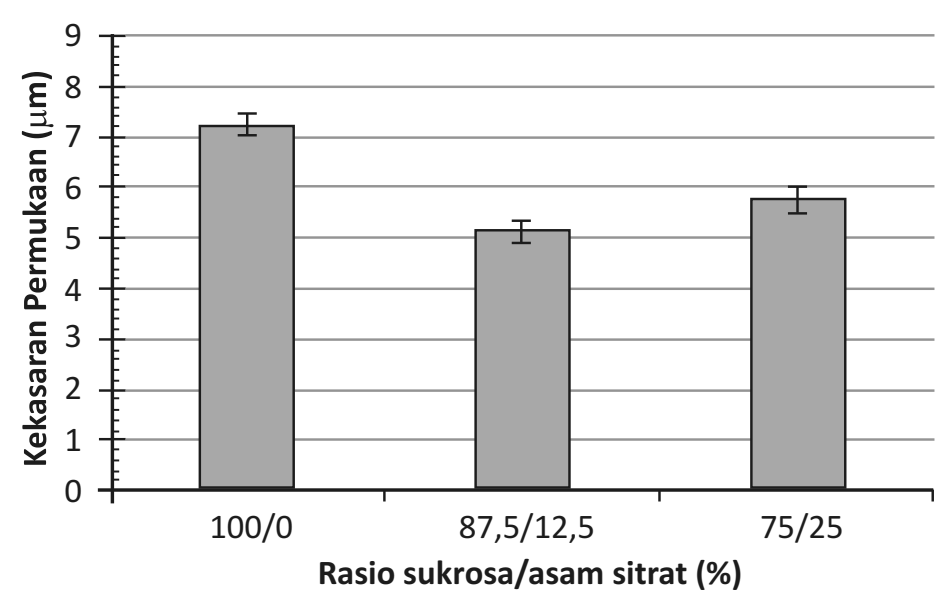

Gambar 3. Histogram kekasaran permukaan papan partikel pelepah nipah. Garis vertikal pada bar merupakan standar deviasi. 


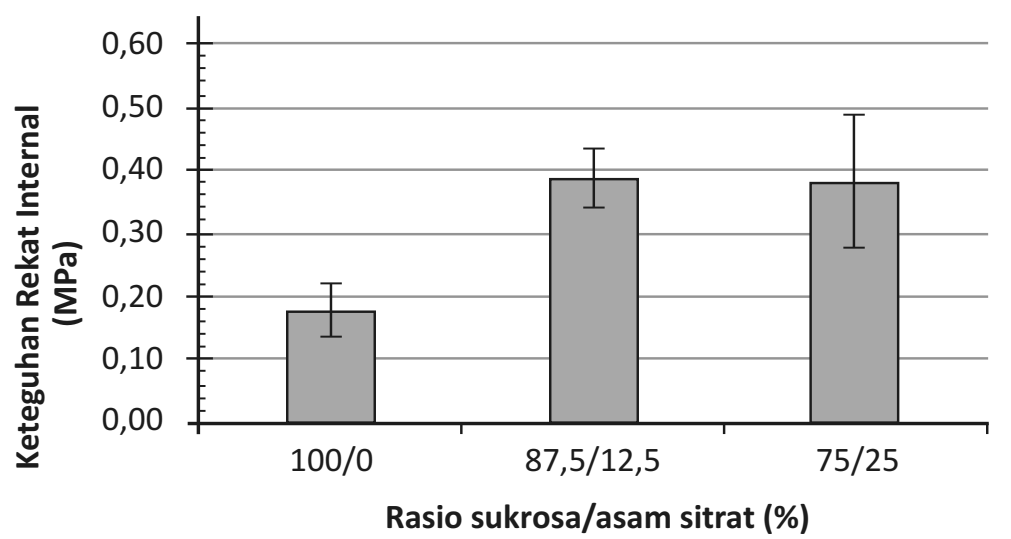

Gambar 4. Histogram keteguhan rekat internal papan partikel pelepah nipah. Garis vertikal pada bar merupakan standar deviasi.

pelepah nipah tanpa kulit dengan menggunakan perekat asam sitrat $10 \%$. Perbedaan ini disebabkan oleh tiga faktor yaitu jenis perekat, jumlah perekat dan komposisi bahan baku. Penambahan asam sitrat pada sukrosa dalam penelitian terbukti efektif meningkatkan sifat rekat papan partikel pelepah nipah dan meningkatkan kadar perekat maksimum (mencapai 20\%) yang dapat diaplikasikan pada pelepah nipah. Sebagaimana disebutkan dalam hasil penelitian Widyorini et al. (2012), kadar perekat asam sitrat maksimum yang bisa ditambahkan ke pelepah nipah hanya sekitar $10 \%$ dan jika lebih dari itu maka papan partikel yang dibuat mengalami delaminasi. Faktor adanya kulit pada pelepah nipah dalam penelitian ini juga berpengaruh positif terhadap keteguhan rekat internal papan partikel pelepah nipah. Jika dihubungkan dengan kandungan zat ekstraktif, maka perbedaan perlakuan dengan dan tanpa kulit ini diduga berpengaruh besar, sehingga pada akhirnya akan memberikan hasil yang berbeda pada keteguhan rekat internal papan partikel pelepah nipah. Demikian juga dengan ukuran dominan partikel penyusun papan partikel, dimana pada penelitian Widyorini et al. (2012), partikel dominan berukuran 10-40 mesh persentasinya sekitar $46 \%$, sedangkan dalam penelitian ini partikel dominan berukuran 10-40 mesh persentasinya mencapai $69 \%$. Hashim et al. (2010) menyatakan bahwa nilai keteguhan rekat internal papan partikel batang kelapa sawit dengan geometri dan ukuran kasar 49\% lebih baik dibandingkan dengan partikel yang berukuran lebih halus.

\section{Keteguhan lengkung statik}

Nilai keteguhan lengkung statik meliputi keteguhan patah dan keteguhan elastisitas. Nilai rata-rata keteguhan patah dan keteguhan elastisitas papan partikel pelepah nipah disajikan pada Gambar 5. Perbedaan jenis perekat yang dipergunakan tidak berpengaruh terhadap keteguhan patah tetapi berpengaruh nyata terhadap keteguhan elastisitas papan partikel pelepah nipah. Nilai keteguhan patah dan keteguhan elastisitas dalam penelitian ini telah memenuhi standar JIS 5908:2003.

Nilai keteguhan lengkung statis papan partikel pelepah nipah hasil penelitian ini lebih baik jika dibandingkan dengan hasil penelitian Widyorini et al. (2012) pada pelepah nipah tanpa kulit. Kemungkinan adanya perbedaan komposisi kimia pada bahan baku (tanpa kulit dan dengan kulit) terutama kandungan ekstraktif diduga berperan dalam menghasilkan nilai yang berbeda ini, demikian juga dengan perbedaan ukuran dan geometri partikel diduga kuat berpengaruh terhadap perbedaan hasil penelitian ini. Hashim et al. (2010) menyatakan bahwa nilai keteguhan patah papan partikel batang 


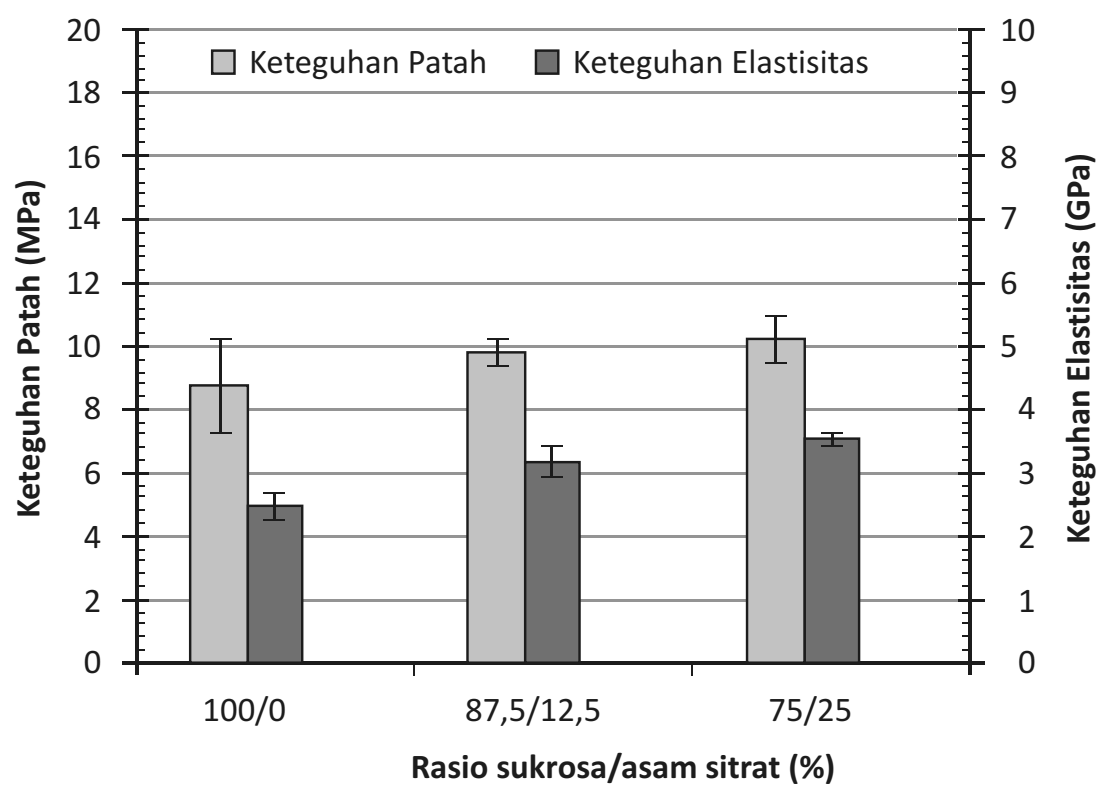

Gambar 5. Histogram keteguhan lengkung statis papan partikel pelepah nipah. Garis vertikal pada bar merupakan standar deviasi.

kelapa sawit dengan geometri dan ukuran yang lebih kasar $84 \%$ lebih baik dibandingkan dengan partikel yang berukuran lebih halus. Faktor lain yang juga berpengaruh besar ialah komposisi perekat dan jumlah perekat yang diaplikasikan pada papan partikel.

\section{KESIMPULAN}

Penambahan asam sitrat pada sukrosa terbukti memberikan pengaruh positif terhadap sifat rekat papan partikel pelepah nipah. Papan partikel paling optimal dalam penelitian ini ialah papan partikel yang direkat dengan sukrosa/asam sitrat 87,5/12,5 ditandai dengan terpenuhinya semua parameter pada standar JIS A 5908:2003. Karakteristik papan partikel dengan perekat sukrosa/asam sitrat 87,5/12,5 dalam penelitian ini ialah kerapatan $0,89 \mathrm{~g} / \mathrm{cm}^{3}$, kadar air 10,21\%, pengembangan tebal 2,45\%, penyerapan air 23,55\%, kekasaran permukaan 5,13 $\mu \mathrm{m}$, keteguhan rekat internal 0,39 MPa, keteguhan patah 9,80 MPa dan keteguhan elastisitas 3,19 GPa.

\section{DAFTAR PUSTAKA}

Bock K \& Lemieux RU. 1982. The conformational properties of sucrosein aqueous solution: Intramolecular hydrogen-bonding. Carbohydrate Research 100(1),63-74.

Harifi T \& Montazer M. 2012. Past, present and future prospects of cotton cross-linking: New insight into nanoparticles. Carbohydrate Polymers 88, 1125-1140.

Hashim R, Saari N, Sulaiman O, Sugimoto T, Hiziroglu S, Sato M, \& Tanaka R. 2010. Effect of particle geometri on the properties of binderless particleboard manufactured from oil palm trunk. Materials and Design 31, 4251-4257.

Hiziroglu S, Suzuki S. 2007. Evaluation of surface roughness of commercially manufactured particleboard and medium density fiberboard in Japan. Journal of Material Processing Technology 184, 436-440.

Hiziroglu S. 1996. Surface roughness analysis of wood composites: a stylus method. Forest Product Journal 46, 67-72.

Indrawan DA, Roliadi H, Tampubolon RM \& Pari, G. 2013. Penyempurnaan sifat papan serat kerapatan sedang dari pelepah nipah dan campurannya dengan sabut kelapa. Jurnal Penelitian Hasil Hutan 31(2), 120-140.

Japanese Industrial Standard. 2003. JIS A 5908-2003 particleboards.Japanese Standard Association, Tokyo. 
Kruse K \& Frühwald A. 2001. Properties of nipa and coconut fibers and production and properties of particle and mdf-boards made from nipa and coconut. Bundesforschungsanstalt für Forst- und Holzwirtschaft Nr 04, Hamburg.

Lamaming J, Sulaiman O, Sugimoto T, Hashim R, Said N, \& Sato M. 2013. Influence of chemical components of oil palm on properties of binderless particleboard. BioResources 8(3), 3358-3371.

Lempang M. 2013. Produksi nata fruticans dari nira nipah (Nypa fruticans Wurmb.). Jurnal Penelitian Hasil Hutan 31(2), 110-119.

Roliadi H, Indrawan DA, Pari G \& Tampubolon RM. 2012. Potensi teknis pemanfaatan pelepah nipah dan campurannya dengan sabut kelapa untuk pembuatan papan serat berkerapatan sedang. Jurnal Penelitian Hasil Hutan 30(3), 183-198.

Subiandono E, Heriyanto NM, \& Karlina E. 2011. Kajian potensi (Nypa fruticans Thumb.) sebagai pangan dan energi dari rutan mangrove. Buletin Plasma Nutfah 17(1), 54-60.

Tamunaidu P \& Saka S. 2011. Chemical characterization of various parts of nipa palm (Nypa fruticans). Industrial Crops and Products 34, 1423-1428.

Umemura K, Ueda T, Munawar SS, \& Kawai S. 2012. Application of citric acid as natural adhessive for wood. Journal of Applied Polymer Science 123, 1991-1996.

Umemura K, Sugihara O, \& Kawai S. 2013. Investigation of a new natural adhesive composed of citric acid and sucrose for particleboard. Journal of Wood Science 59, 203-208.

Umemura K, Sugihara O, \& Kawai S. 2014. Investigation of a new natural adhesived composed of citric acid and sucrose for particleboard II: Effect of board density and pressing temperature. Journal of Wood Science 61,40-44.

Widyorini R, Prayitno TA, Yudha AP, Setiawan BA \& Wicaksono BH. 2012. Pengaruh konsentrasi asam sitrat dan suhu pengempaan terhadap kualitas papan partikel dari pelepah nipah. Jurnal Ilmu Kehutanan 6(1), 61-70.

Widyorini R, Umemura K, Isnan R, Putra DR, Awaludin A, \& Prayitno TA. 2016a. Manufacture and properties of citric acid-bonded particleboard made from bamboo materials. European Journal of Wood and Wood Products 74, 57-65.
Widyorini R, Pradana PA, Muhammad ZAR, \& Prayitno TA. 2016b. Bonding ability of a new adhesive composed of citric acid-sucrose for particleboard. BioResources 11(2), 4526-4535. 